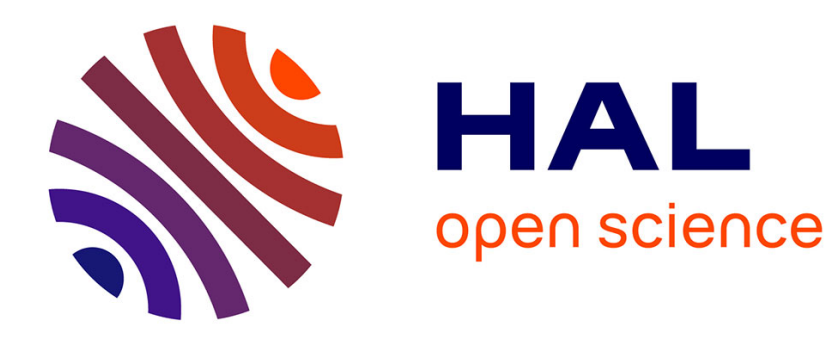

\title{
On the nature of 'context' in chemical education
}

John K. Gilbert

\section{To cite this version:}

John K. Gilbert. On the nature of 'context' in chemical education. International Journal of Science Education, 2007, 28 (09), pp.957-976. 10.1080/09500690600702470 . hal-00513318

\section{HAL Id: hal-00513318 \\ https://hal.science/hal-00513318}

Submitted on 1 Sep 2010

HAL is a multi-disciplinary open access archive for the deposit and dissemination of scientific research documents, whether they are published or not. The documents may come from teaching and research institutions in France or abroad, or from public or private research centers.
L'archive ouverte pluridisciplinaire $\mathbf{H A L}$, est destinée au dépôt et à la diffusion de documents scientifiques de niveau recherche, publiés ou non, émanant des établissements d'enseignement et de recherche français ou étrangers, des laboratoires publics ou privés. 


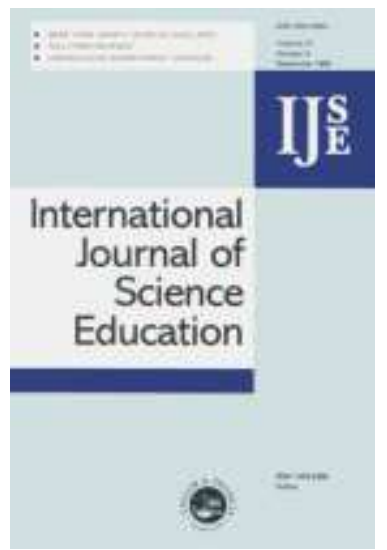

\section{On the nature of 'context' in chemical education}

\begin{tabular}{|r|l|}
\hline Journal: & International Journal of Science Education \\
\hline Manuscript ID: & TSED-2006-0054 \\
\hline Manuscript Type: & Special Issue Research Paper \\
\hline Keywords: & chemistry education, curriculum \\
\hline Keywords (user): & context-based \\
\hline
\end{tabular}

\section{S) ScholaroNE \\ Manuscript Central}




\title{
On the nature of 'context' in chemical education
}

\author{
John K. Gilbert, Institute for Education, The University of Reading, UK
}

\begin{abstract}
Some of the most pressing problems currently facing chemical education throughout the world are rehearsed. It is suggested that, if the notion of 'context' is to be used as the basis for an address to these problems, it must enable a number of challenges to be met. Four generic models of 'context' are identified that are currently used or which may be used in some form within chemical education as the basis for curriculum design. It is suggested that a model based on physical settings, together with their cultural justifications, and taught with a socio-cultural perspective on learning, is likely to meet those challenges most fully. A number of reasons why the relative efficacies of these four models of approaches cannot be evaluated from the existing research literature are suggested. Finally, an established model for the representation of the development of curricula is used to discuss the development and evaluation of context-based chemical curricula.
\end{abstract}

\section{Preface}

This paper is an attempt to characterise and evaluate the four models of 'context' that underlie recent attempts to reform the design of courses in chemical education. As such it 
connects different theoretical notions: An overview of the challenges that chemical education currently faces and what the notion of context must do to address them; A model of the attributes of any context (Duranti \& Goodwin, 1992); A theory about situated learning that may be applied to context-based curricula (Greeno, 1998); Criteria for the successful attainment of context-based learning; and for curriculum representations described by Goodlad (1979) and by Van den Akker (1998) to be applied to context-based curricula.

\section{Context as an address to challenges}

\section{Challenges and 'context'}

Throughout the world, over the past twenty years or so, chemical education has faced a number of inter-related problems:

\section{Overload}

As a consequence of the ever-accelerating accumulation of scientific knowledge, curricula have become over - loaded with content (Millar \& Osborne, 2000; Rutherford \& Ahlgren, 1990). The consequences of high content loads have been that curricula are too often aggregations of isolated facts detached from their scientific origin (De Vos, Bulte, \& Pilot, 2002).

\section{Isolated Facts}


These curricula are being taught without students knowing how they should form connections within and between the aggregations of isolated facts. The acquisition of a large number of isolated facts does not lend itself to the formation of mental schema. Students cannot acquire a sense of how to give meaning to what they are learning. This can only lead to low engagement in classes and the forgetting of material thereafter.

\section{Lack of transfer}

Students can solve problems presented to them in ways that closely mirror the ways in which they were taught. They signally fail to solve problems using the same concepts when presented in different ways. There is little or none of that transfer of learning that is a preparation for the life-long learning of chemistry or its uses in everyday life (Osborne \& Collins, 2000) (p. 21).

\section{Lack of relevance}

When chemistry ceases to be a compulsory subject in the curriculum (usually at the minimum school-leaving age), the great majority of students does not elect to continue to study it. Moreover, many of those that do elect to continue to study the subject experience a lack of relevance in it and seem to view it in an instrumental way, rather than because it is worthwhile in itself. It is this latter approach that would give them a sense why they should learn the required material. At best, chemistry has become a prerequisite for the study of something in which they are actually interested e.g. medicine.

\section{Inadequate emphasis}


The traditional emphases of the chemistry curriculum have been the provision of a 'solid foundation' ('the cumulative development of propositional knowledge---so that one can understand---the next science course'), 'correct explanation' ('science is the correct explanation of the world'), and 'scientific skill development ('using the right processes-- will---inevitably produce reliable knowledge') (Roberts \& Ostman, 1998)(p. 6-10) as the basis for more advanced study of chemistry. However, this set of emphases is, on its own, increasingly seen as an inadequate basis for such study. It is also an inappropriate basis for the chemical education of the majority of students who will not continue to study the subject, especially where the overall goal is the development of 'scientific literacy'(Laugksch, 2000).

Each of these problems poses a series of challenges. A major address to these challenges has been through the use of 'context' as the basis for curriculum design and classroom teaching. For this to be successful, the educational model that embodies the meaning of 'context' must be such that it provides an effective answer to the associated curricular and social problems.

To address the first problem, the use of context should simplify and / or reduce the content load of the curriculum. We need to identify those concepts which are most widely used throughout chemistry and to concentrate learning on them. The content load of the chemical curriculum could then be lightened by focusing on contexts which exemplify those concepts. Thus, the collection of contexts used must be such that a parsimonious 
selection of the concepts to be taught can be made from the broad range available within chemistry per se.

Secondly, the collection of contexts used must be able to provide the basis for the development of coherent 'mental maps' of the relationship between these concepts by students. Approaches based on variations of the educational psychology of 'constructivism' (e.g. personal constructivism, social constructivism, situated learning, activity theory) are currently believed by many to address these issues (Glaserfeld, 1989; Kelly, 1955; Vygotsky, 1978), albeit with reservations by some (Matthews, 1995; Osborne, 1996; Solomon, 1994). Yet this throws up a series of issues: how can such techniques be implemented effectively when classes remain very large, very diverse in prior attainment and in future intentions?

Thirdly, the collection of contexts used must be such that the teaching of concepts in a given context will increase the likelihood that those concepts will be transferred by students to the understanding of other contexts. Students must be able to perceive analogies between the learning demands of the contexts facing them.

\footnotetext{
For an effective address to the fourth issue, all students need to become sufficiently involved in the work at hand with some students becoming very interested in it. For all students, the collection of contexts used must make chemistry more relevant and enable the development of a sense of ownership of that which is to be learnt. The structure of the curriculum must be such that it, at best, resonates with students' present and anticipated
} 
interests, and, at worst, is capable of engendering interest and commitment. Students will then be both more willing and able to engage in chemical education when compelled to do so, as well as being more inclined to continue voluntarily with it.

Finally, other curriculum emphases must be addressed and a better balance between all of them achieved to facilitate an effective chemical education for all. Roberts and Ostman have identified other, very infrequently occurring, emphases in curricula: 'everyday coping' ('a way of making sense of objects and events of fairly obvious everyday importance'), 'self as explainer' ('the focus is on explaining as a process, on what influences the ways people explain'), 'science, technology, and decisions' ('science has limitations in the practical arena of trying to make decisions'), and 'structure of science' ('aspects of the growth and appraisal of scientific knowledge') (Roberts \& Ostman, 1998)(p. 6-10). The inclusion of a higher proportion of these latter would broaden the base of chemical education. The overall collection of contexts used must be sufficiently flexible as to permit the design of curricula for groups of students with a wide range of prior attainments and future ambitions in chemistry. It should be noted that all adult learning of all the sciences takes place in these conditions.

\section{Criteria for the use of 'context' in chemical education}

If the use of 'context' is to be promoted as a way of resolving the problems of the chemistry curriculum, the meaning of the word itself needs clarification. The everyday 
meanings are 'the circumstances that form the setting for an event, statement, or idea, and the terms in which it can be fully understood' and 'the parts that immediately precede or follow a word or passage and clarify its meaning' (Pearsall, 1999).The word originates from the Latin language in the verb 'contexere', 'to weave together'. In its related noun 'contextus' the word expresses 'coherence', connection' and/or 'relationship'. Thus, the function of 'context' is to describe such circumstances that give meaning to words, phrases and sentences. A context must provide a coherent structural meaning for something new that is set within a broader perspective. These descriptions are consistent with the function of 'the use of contexts' in chemical education: students should be able to provide meaning to the learning of chemistry; they should experience their learning as relevant to some aspect of their lives and be able to construct coherent 'mental maps' of the subject.

Duranti and Goodwin, building on this perspective with the use of the tools of linguistics, see a precise definition of 'context' as an impossible task:

\footnotetext{
‘...it does not seem possible at the present time to give a single, precise, technical definition of context, and eventually we might have to accept that such a definition may not be possible' (Duranti \& Goodwin, 1992)(p. 2)
}

\begin{abstract}
However, they do offer us some useful clues. They see 'talking' as the behaviour that a context is normally invoked to interpret (p.3). Non-verbal behaviour, such as the use of a diagram, an animated model, or a photograph, can create a context in which talk then
\end{abstract}


takes place: this they call a 'focal event', an event that gets attention and is put in the spotlight.

A context is then a focal event embedded in its cultural setting (p.3). Consequently, they see an educational context to have four attributes:

a. a setting, a social, spatial, and temporal framework within which mental encounters with focal events are situated;

b. a behavioural environment of the encounters, the way that the task(s), related to the focal event, have been addressed, is used to frame the talk that then takes place;

c. the use of specific language, as the talk associated with the focal event that takes place;

d. a relationship to extra-situational background knowledge (p.6/8).

These attributes can be clarified with the aid of an example that could be based on the practical world of science / technology: the focal event of thinking about an earthquake that has taken place somewhere on our planet. Then a setting (attribute a) could be the devastated area that requires rebuilding; how the framing of this is determined by the type of society in the country(s) involved, the population density and distribution, the imminence of bad weather. The behavioural environment (attribute b) is then the type of activities engaged in by architects, materials scientists, and city-planners as they use resources and methods that are thought necessary for the task(s) of constructing new buildings. This determines the language used (attribute c): the need for earthquake 
resistant houses, the use of concrete rather than more fragile materials, and the notion of flexible structures for buildings. The background knowledge involved (attribute d) is then concerned with the action of uneven forces on buildings, the composition of concrete for specific purposes, the redistribution of forces in flexible houses.

A second example, fully developed in the field of chemical education, is the treatment of 'The chemistry of global warming' given in (Stanitski, Eubanks, Middlecamp, \& Pienta, 2003) (p.98-144). Taking the four attributes in turn:

Attribute a: Where, when, how is the focal event situated? The focal event is the general phenomenon of global warming, manifest throughout the world in different ways.

Attribute b: What do people do in this situation; what actions do they take? Various measures to reduce the production of relevant gases are discussed, as are measures to remove those already in the atmosphere.

Attribute c: In what language do people speak about their actions? The molecular structures of relevant gases are discussed, with a particular emphasis on the way that internal vibrations lead to the effects that are observed.

Attribute d: What is the background knowledge of those who act? The need for a general education about molecular structure and energy conversion is required.

These four attributes of context can be used to address the five challenges facing chemical education. The curriculum overload ( $1^{\text {st }}$ challenge $)$ can be reduced by selecting focal events that are relevant for students ( $4^{\text {th }}$ challenge) and those parts of "chemical language' (concepts) that are needed for students to grasp the meaning of the chemistry 
involved in these focal events ( $2^{\text {nd }}$ challenge). This leads to the following interpretation of the attributes as preliminary criteria for context-based chemistry education, taking the possible pollution of swimming water as an example for a focal event.

a) Students must recognise and value the setting as a social, spatial, and temporal framework within which they encounter focal events of the domain of chemistry.

In the example of the (potential) pollution of swimming water as the focal event, the setting can be the potentially polluted river or lake in the close environment of students, which they feel is of concern to them. The students' recognition of such setting is as a condition for engaging in the behavioural environment provided ( $4^{\text {th }}$ challenge).

b) The behavioural environment determines the typical tasks in the domain of chemistry that are to be engaged in: developing and executing research plans, chemical analysis, and experimental laboratory skills which include chemical concepts, and principles.

For the chosen focal event, it requires first that students should be able to accept that water samples should be taken from a certain river or lake; and second that these should be tested followed by an evaluation and decision-making to decide that 'there is no dangerous stuff' in the water and that it is safe to swim in It involves the whole range of activities that are needed to make a valid decision about water quality, the concepts, relations (calculations), skills (precise handling and measuring) and attitudes (appreciating the reliability of results). 
c) The nature of the behavioural environment frames the chemical talk that students should learn to use.

In the example this involves specific terms such as turbidity, $\mathrm{pH}$, colorimetric analysis, norms for E-coli concentration, the representative sampling of swimming water.

This choice is related to the $5^{\text {th }}$ challenge; it sets the emphasis and determines the perspective with which concepts and principles are used. The chemical talk is thus embedded in a relevant setting (attribute a) with which the behavioural environment (attribute b) provides for coherence when using chemical talk. This is related to the $2^{\text {nd }}$ challenge.

d) The chemical behavioural environment and the specific chemical language are related to chemical knowledge that is relevant and used in other focal events in the chemistry domain. This attribute is related to the $3^{\text {rd }}$ challenge (transfer) by teaching students to place a focal event in a broader perspective. In the example this might involve more general knowledge such as concentration, norms, mean, nitrite etc., which can be used when students have the task to determine the quality of milk, fruit juices, or other products.

\footnotetext{
These attributes of a focal event (the context) seem to address the five curricular challenges. When a context provides a coherent structural meaning for the students by way of the elaboration of each of the four attributes, it can be expected that the personal relevance for the students will be related to an understanding of why they are learning about chemistry. However, this classification does not focus sufficiently sharp on how
} 
'learning' should actually take place. Therefore we need to turn to theories in educational psychology for a more precise understanding how the attributes of 'context' should be implemented in context-based chemistry education.

\section{Approaches to the making of meaning}

Of the many alternatives available, three approaches to the making of meaning, each building on the predecessor, seem of particular importance for the use of 'contexts': the general approach known as constructivism, situated learning, and activity theory. These can then be applied within the design of 'context-based' learning environments.

\section{Constructivism}

The broad collection of theories known as 'constructivism' provides a general way of addressing the attributes c and d. Ogborn (1997) discusses the importance of learners actively constructing their knowledge, expressed in learning the chemical talk related to the task (attribute c), and acquiring background knowledge in general (attribute d). Educational constructivist approaches insist on four points: the importance of pupils' active involvement in thinking if anything like understanding is to be reached; the importance of respect for the student and for the student's own ideas, the notion that science consists of ideas created by human beings; and a design of teaching that gives 
high priority to the making sense by students, capitalising and using what they know, and addressing difficulties that may arise from how they imagine things to be (Ogborn, 1997).

Situated learning

The ideas of 'situated learning' (Greeno, 1998) are a useful way of discussing how the attributes a - $\mathrm{d}$ provided by particular contexts can be connected to context-based chemistry education.

\begin{abstract}
A. Participation in a community of practice.
The teacher and students must conceive of themselves as acting collectively as a ‘community of learners'. For this, Greeno characterises communities of practice as 'Regular patterns of activity in a community, in which individuals participate' (p.6).
\end{abstract}

B. The condition for effective participation is that students and teachers develop their identity through productive interactions.

The value of such participation must be recognised by both teacher and student as crucial in supporting the development of a student's identify as a learner. According to Greeno 'Regularities of an individual's activities, in a trajectory that gives participation at different times in a community and participation in different communities, are characterised as an individual's identity' (p.6). 
The achievement of a high quality in the interactions involving a student must be recognised by all participants as crucial in developing that identity. Greeno states that 'affordances are qualities of systems that can support interactions and therefore present possible interactions for an individual to participate in' (p. 9).

Student activity, if learning is to be achieved, must involve becoming increasingly sensitive to the potential value of interactions. 'Learning, in the situative view, is hypothesised as becoming more attuned to the affordances of activity and becoming more centrally involved in the practices of a community' (p.11).

High value situations must be identified and concentrated on, for every situation considered in a class has attendant scope and limitations for the facilitation of learning: 'constraints....regularities of social practices and of interaction with material and informational systems that enable a person to anticipate outcomes and to participate in trajectories of outcomes' (p. 9). In short, given that different situations will be different in the ease with which they support situated learning, only those that readily meet the criteria set out here should be employed.

Students must aspire to a high quality of learning by valuing the interactions taking place. Greeno states that: 'Regular patterns in a individual's participation can be conceptualised as that person's attunement to affordances and constraints'(p.9).

C. Learning is situated, but the outcomes of a learning situation must be transferred across situations.

The most valuable outcome of learning is to be able to transfer ideas across situations and must be actively sought. According to Greeno: 'transfer is hypothesised to depend on 
attunement to constraints and affordances that are invariant or modifiable across transformations of a situation where learning occurred to another situation in which learning can have an effect'(p.11).

Teachers and students must recognise that all learning is situated, so the nature of the learning environment is all-important: 'The differences between learning in different arrangements is not whether learning is situated or not, but how it is situated' (p.14).

D. The quality of a task is a condition for participation in a community of practice. Greeno stresses that: "engagement...having a positive orientation towards activities of learning and construction of knowledge, involves issues of affiliation and identity in communities of practice' (p.10). 'Because students learn how to participate in the practices of learning...it is important to attend to the kinds of participation in learning that are afforded and valued in schools' (p.14).

Those learning environments that are based on problem-solving pedagogies are crucial if reasoning skills are to be developed. Greeno actually connects the attributes a (setting), b (behavioural environment), c (the talk) and d (the background knowledge), when he states that '... (opportunity to participate in practices of enquiry) involve students reasoning in the target subject-matter domain and reasoning with the concepts and methods of the target subject-matter domain' (p.15).

One of the main tenets of situated learning as applied to the notion of 'learning in a context' is thus that mental links have to be made by a learner between a setting (attribute 
a) that is the vehicle for learning and the concepts involved in that understanding (attributes c \& d). As indicated by Greeno, a mechanism for such a linkage can be provided the idea of 'activity'.

\section{Activity theory}

In Vygotsky's account (Vygotsky, 1978), the learner and the object being studied are not separate entities; they mutually define each other during human activity. The learner makes meaning for an object by use of a particular interpretation of the topical conditions of that person's life. That making of meaning itself alters the general conditions of the person's life, albeit usually only to a small extent (Van Oers, 1998) (p. 479). Here the object is the focal event that is being studied. The learner enters into a 'cognitive apprenticeship' with the teacher who is an expert in interpreting the setting (the focal event).The teacher's task is to bring together the socially accepted understanding of the focal event being studied and the ideas about it that the students have. Put another way, the teacher needs to bring together the socially accepted attributes of a context and the attributes of a context as far as these are recognised from the perspective of the students. The mental arena in which this takes place effectively is the 'zone of proximal development' of the individual student (Becker \& Varelas, 1995; Confrey, 1995). Identifying the parameters of the 'zone of proximal development' in respect of a given focal event for students of different attainments, or identifying the learning outcomes for 
students of similar attainments to be achieved through different focal events, are major tasks that must be addressed in the future.

\section{Revisiting the attributes of a context: criteria for the attainment of context-based learning of chemistry}

The attributes of context according to Duranti and Goodwin, which are now taken as a framework for context-based learning, are in line with Finkelstein's framework of context (2005). She distinguishes: task (attribute b), situation and idioculture as a broader conceptualisation of situation (attribute a). Finkelstein considers these frames of context as conditions for effective learning.

Together with the use of the several theories of learning outlined above, the four attributes of a context can now be rephrased to make them criteria for the attainment of context-based learning of chemistry. This implies the transition from a description of context with its attributes (a) to (d) as perceived by 'experts' into a more normative prescription of how to use 'contexts' for the purposes of designing learning environments the criteria (i) to (iv) respectively:

i. Students must value the setting as a social, spatial, and temporal framework for a community of practice. They must value their participation in a community of practice through productive interaction and develop personal 
identities from the perspective of that community. The community of practice must provide a framework for the setting of focal events, as described by socio-cultural theory (Greeno, 1998). In terms of activity theory, the setting provided must lie in the zone of proximate development of the student (Vygotsky, 1978). The nature of this zone must be expected by the teacher to be different at different stages in the curriculum. These settings must clearly arise from the everyday lives of the students (Braund \& Reiss, in press; Kasanda et al., in press; Mayoh, 1997), or social issues and industrial situations that are both of contemporary importance to society.

ii. In order to be of high quality, the learning task must clearly bring a specifically designed behavioural environment into focus, since the way the task is being addressed, the type of activity engaged in, is used to frame the talk that then takes place (Greeno, 1998; Vygotsky, 1978). The task form (Finkelstein, 2005) must include problems that are clear exemplifications of chemically important concepts.

iii. Learners should be enabled to develop a coherent use of specific chemical language. Through the talk associated with the focal event that takes place, students should reach an understanding of the concepts involved. They should also come to acknowledge, in accordance with the general ideas of constructivism, that such specific language is a creation of human activity. With respect to idioculture (Finkelstein, 2005), the teacher must know the background knowledge of the students. 


\author{
iv. Learners need to relate any one focal event to relevant extra-situational, \\ background knowledge, building productively on prior knowledge which is, \\ partially at least, composed of the learner's own ideas. They must be enabled \\ to 'resituate' (Greeno, 1998) or 'recontextualise' (Van Oers, 1998) specific \\ language in order to address the focal event at hand. A vital source of focal \\ events will be those with major public policy implications e.g. global \\ warming; stem-cell biology.
}

\begin{abstract}
With these criteria in mind, how then can the use of 'context' facilitate the acquisition of meaning during the learning of chemistry?
\end{abstract}

\title{
Evaluating four models of 'context'
}

Four canonical models of 'context' can be teased out that seem to be used, or which might be used, in chemical education. Each of these is presented below in terms of: the notion of 'context' that implicitly or explicitly underpins it, and the extent to which the criteria for successful context-based learning are met. Providing convincing examples of all the models is difficult for two reasons. First, few context-based courses have historically been based on an explicit model of context. Second, there is a general lack of research of any kind into chemical education, such that it is often only the descriptions of courses, provided by the developers, which are available. Third, in all curriculum innovation, there seems to inevitably be a gap between aspiration and realisation. Stating 
what ought to be is misleading without, at the very least, the support of case studies of what actually happens in typical classrooms.

\title{
Model 1: Context as the direct application of concepts
}

\begin{abstract}
A common use of the word context is to denote the application of concepts, or the consequences of that application, to illustrate their use and significance. In practical terms, a curriculum based on this meaning consists of situations or events drawn from the presumed personal / social everyday life of the students and/or industrial life to which the concepts of chemistry, taught as abstractions, are then applied in order that the students may understand them more fully. This approach often seems to infer one-directional and rigid relationships between 'concepts' and 'applications': the talk is strictly about how the concepts are used in the applications. Such courses tack on an application, almost as an afterthought, to the end of the theoretical treatment of concepts. The applications - the focal events - always consist of events / situations treated as objects and may, or may not, include a consideration of their cultural significance. To take just one example (to spare the blushes of most textbook authors): in a workshop for the creation of contextbased materials, a teacher said:
\end{abstract}

'after teaching about acidity and alkalinity, I would ask 'what type of solution can you use at home to apply to a wasp sting?' (George \& Lubben, 2002) (p.664) 
This model of context focuses on the abstract learning of a specific language without framing the setting and the behavioural environment in advance. As a post-hoc illustration, it is only an attempt to give meaning to a concept after it has been learnt. This type of model therefore does not meet the criteria for a context-based curriculum because it:

i) does not introduce students to the social, spatial, and temporal framework of a community of practice;

ii) does not provide a high-quality learning task because the behavioural environment is sketchy almost to the point of invisibility;

iii) does not provide a vehicle for students to acquire the coherent use of specific language;

iv) invokes very little background knowledge in any significant manner.

\section{Model 2: Context as reciprocity between concepts and applications}

In this view, not only are concepts related to their applications but those applications also affect the meaning attributed to the concepts. The context is formed by the juxtapositioning of concept and application in a students' cognitive structure. Meaning is created by the acquisition of relevant aspects of the structure of chemical knowledge. Within this model of context, several sub-groups of chemical context can be distinguished: e.g. the context of chemical knowledge of a biochemist; the context of the chemical knowledge of a chemical technologist; the context of ethical social-scientific 
issues. An explicit (even an implicit) shift between sub-groups can imply a different meaning for a concept. It can also lead to confusion by students and even by teachers.

This greater degree of reciprocity in that relationship of concepts and applications is partially inferred in the broad definition of content used the Science-Technology-Society movement:

'STS content in a science education curriculum is comprised of an interaction between science and technology, or between science and society, and any one or combinations of the following:

- a technological artefact, process, or expertise

- the interactions between technology and society

- a social issue related to science or technology

- social science content that sheds light on a societal issue related to science and technology

- a philosophical, historical, or social issue within the scientific or technological community' (Solomon \& Aikenhead, 1994)(p. 52-53)

David Layton has discussed how the meaning attached to a concept in a science may be changed when it is used in technology (Layton, 1993). For example, in chemistry 'pure water' is a single substance not containing other substances and having specific thermodynamic properties. On the other hand, in environmental chemistry, 'pure water' is water that is safe to drink because it does not contain any toxins. 
This model of 'context' provides a 'mental surrounding' to which subsequent ideas can be related (Van Oers, 1998). De Vos et al. (2002) have drawn our attention to the fact that the existing chemical curriculum has a sedimentary structure consisting of successive layers of contexts introduced in this way at different historical periods. It is therefore possible to perceive why students find the subject so confusing when this model is used. It also explains why Roberts claims that, for any one curriculum-unit, only one curriculum emphasis should be brought into focus (Roberts, 1988, p38).

This model does provide a sounder basis for context-based chemical education than the first model because:

i) although there is no obvious need for students to value the setting as the social, spatial, or temporal framework for a community of practice,

ii) the behavioural environment may be of a higher quality, dependent on the teacher's understanding of the setting being used,

iii) and students can be given the opportunity to acquire a coherent use of specific language,

iv) and they can be enabled to relate what is learnt to their own prior understandings.

\begin{abstract}
What is missing from this model is any overt rationale for the selection of focal events, or for the phased introduction of concepts into lessons on a need-to-know basis: criterion $\mathrm{i}$ is not met and criterion iii may be under-addressed. This omission re-emphasises the earlier
\end{abstract}


remark that, in Vykotsky's view, the teacher needs to bring together the socially accepted attributes of a context and the attributes of a context as recognised from the perspective of the students. For experts working within a certain 'context', their motives for actions are clear, they see the point of why it is necessary to address a certain problem within the focal event. Students do not necessarily see a relation / connection between a certain problem and why they should learn / use some chemistry to deal with it. In other words the 'context' of an expert does not automatically become the 'context' of learner.

Model 3: Context as provided by personal mental activity

An attempt to adopt this approach, using the ideas of personal construct psychology (Pope \& Keen, 1981), was made by Stocklmayer and Gilbert. They devised a model, using different terminologies to those employed earlier in this paper, consisting of the three elements that would provide the 'keys to successful informal chemical education' (Stocklmayer \& Gilbert, 2002) (p.145):

- 'Situations' : these are the 'settings' for 'focal events' in Duranti and Goodwin's (1992) terms.

- 'Contexts': these are produced by the transformation of 'situations' through personal mental activity. The emphasis is on the use of existing mental models to impose meaning on the settings. The 'talk', in Duranti and Goodwin's (1992) terms, is intra-personal. 
- 'Narratives': these are links made between 'contexts' and some on-going theme in the life of the learner. These links imply the transfer of learning from the immediate setting to other, in some way analogous, settings, using Duranti and Goodwin's (1992) terms.

- To unite several of Duranti and Goodwin's (1992) terms: a focal event is embedded into a personal setting (attribute a) and the intra-personal talk (attribute c) invokes background knowledge (attribute d).

Stocklmayer and Gilbert (2002)(p.146) identified several examples of books, intended to provide informal chemical education, to which their model seemed to apply. For example, by taking Mendeleyev as a person fixed in time and space who was seeking to represent the periodicity of the properties of chemical elements, Strathern was able to weave a successful story that could be interpreted in terms of 'narrative', 'context' and 'situation' (Strathern, 2000).

In terms of the criteria for successful context-based chemical education through the medium of a book:

i) The use of a narrative as a framework for an account of historical events in chemistry would only be successful if students saw the value of it. Where this took place, the model would meet this criterion if the students could empathise with the community of practice being described. 
ii) It would require considerable guidance by the teacher if the activities and talk built around the book were to be effective.

iii) The specialist language of the field could be effectively developed and used.

iv) A great deal of background knowledge e.g. about the state of chemical knowledge at the time of Mendeleyev, would be needed and this would be unlikely to be available.

On balance, the model seemed to be of greatest value when applied to cases of recent major events in chemistry e.g. the discovery of 'buckyballs'. When the students empathise with this type of context, they can value the description of it. However, they do not become actively involved. The social dimension of engagement through interaction within a community of practice is missing (criterion i).

\section{Model 4: Context as the social circumstances}

In this view, the social dimension of a context is essential. A context is situated as a cultural entity in society. It relates to topics and people's activities which are considered of importance to the lives of communities within the society. A context can, for example, be the technological developments based on genetic modification, the scientific research taking place in that field, and the debate about the social implications of the ensuing technology. Other examples are: developments concerning the global climate, 'healthy' food and obesity, the 'hydrogen economy'. 
In this model meaning - making can take place from two slightly different perspectives. Meaning-making can take place by viewing 'a context as social surrounding', or by viewing ‘a context as social activity’ (Van Oers, 1998). In terms of Duranti and Goodwin: giving meaning to the 'talk' that takes place in 'context as social surrounding' is mainly determined by the setting (attribute a). Learning is considered to take place as experiencing a setting. Whereas the individual's meaning-making of the 'talk' in 'context as social activity' is to a large extent being determined by participating in the actions of a community: the behavioural environment (attribute b). Then learning is primarily based on actions: 'The dynamics of activities are founded in the complex interrelationships of motive, means, goal, actions, operation, as they are negotiated among participants in an activity' (Van Oers, p. 480).

\begin{abstract}
In science education, ideas for this model have been developed by Van Aalsvoort (2004), taking the typical activity of 'the production of chemicals' as a guideline for curriculum design. For undergraduate physics education, Finkelstein (2005) (p. 1195) stresses that
\end{abstract}

\footnotetext{
"it is not fruitful to separate student learning from the context in which it occurs; context is not simply a backdrop for student learning. Rather, context is intrinsic to student learning, it shapes and is in tern shaped by both the content and student (who is active in developing an understanding of a given domain and arrives with prior history)".
} 
A similar argument in favour of this model can also be distinguished for 'Realistic Mathematics Education' (Cobb et al., 2001). Here, learning takes place by guided reinvention (Freudenthal, 1973), when the teacher and the students develop socialmathematical norms: a shared purpose, way of reasoning, and mathematical argumentation. Together, teacher and student develop 'mathematical practices'.

Summarising, this model 'context as the social circumstances' is based on situated learning and activity theory.

Such a model would represent a course in which:

i) The teachers and students see themselves as participants of a 'community of practice', with productive interactions on a regular basis. This mutual expectation would enable relevant zones of students' proximal development to be identified and acted upon by the teacher.

ii) This would most readily be met where the course was based on a sustained enquiry in a substantial setting. The learning environment provided by a task of such a nature as to readily facilitate the communal engagement of teacher and students in a genuine, as opposed to a contrived, enquiry.

iii) The task form (Finkelstein, 2005) must include problems that are clear exemplifications of chemically important concepts, to enable learners to develop a coherent use of specific chemical language. 
iv) Arrangements are made for the students to transfer what they have learnt in one focal event to another focal event.

This design of a course is currently very infrequently found, perhaps because of the resource demands that it makes e.g. on teachers' subject knowledge and pedagogical content knowledge (Shulman, 1987) .

In education, there is always a large gap between the emergence of a new theoretical idea and attempts to work out its detailed implications for practice. Although the ideas of situated learning and activity theory have been discussed for about 20 years, curricula based on their premises are only now emerging and being implemented in practice. Those recent developments presented later in this Special Issue can be evaluated in respect of these ideas (Pilot \& Bulte, this issue).

\section{Evaluation of the four models of context}

In summary, I have discussed four models of context. This analysis has been taken place from the linguistic perspective of Duranti and Goodwin, and, with the use of several notions from educational psychology, been transformed into a set of criteria that can represent the actual or possible use of contexts in chemical education.

To what extent and in what ways do each of the four models respond to the challenges, rehearsed earlier, that chemistry education currently faces? Producing a range of models 
of any phenomenon always implies that distinct differences exist between the models identified. The concise representation of such models leads to an increased element of oversimplification, even of parody. However, there does seem to be a steady progression from Model 1 to Model 4 in terms of the extent to which they meet the criteria for successful context-based courses.

\section{Implementation of context-based curricula}

Research

Bennett has provided a summary of research into context-based curricula (Bennett, 2003)(p.114):

- pupils interest in and enjoyment of their science lessons are generally increased when they use context-based materials and follow context-based courses;

- context-based materials help pupils see and appreciate more clearly links between the science they study and their everyday lives;

- pupils following context-based courses learn science concepts at least as effectively as those following more conventional courses;

- a curriculum development model which involves teachers is more effective than the 'centre-periphery' model in effecting changes in practice and alleviating teachers' anxiety when faced with innovation; 
- there is a need for further research into the effects of assessing pupils' scientific knowledge and understanding through the use of context-based questions;

- interest and enjoyment of lessons involving context-based materials does not appear to be translated into a desire to study the subject further, though there are some significant localized exceptions to this.

These conclusions followed from the analysis of four groups of organisational approaches taken to the inclusion of context, however defined, in science curricula overall (Bennett, 2003)(p.103-104) ( a). whole courses based on a series of contexts e.g. Salters Chemistry (Campbell et al., 1994) and Chemistry in Context (Stanitski et al., 2003), (b). the inclusion of units based on contexts as a substitute for conventional treatment of content e.g. the use of 'historical vignettes' (Wandersee \& Roach, 1997), (c). the inclusion of single context-based lessons in a conventional course e.g. SATIS (A.S.E., 1986), and (d). the inclusion of brief context-based 'episodes' in conventional lessons (Mayoh, 1997).

Supporters of the idea of the 'context-based course' will have been somewhat encouraged by these results. However, it is very difficult to bring about large scale changes to the chemistry curriculum. Prospective teachers enter pre-service education with a set of beliefs about chemical education based on their own (successful) experience (Lederman, 1992). Students and their parents have expectations about what chemical education should entail. The use of expository methods of teaching in pre-and in-service courses for teachers, coupled to a lack of effort to educate students and their parents, 
means that traditional ways of teaching, learning, and assessment, are not challenged effectively.

The impact of context-based courses does not, therefore, seem to have been all that their advocates would wish. One reason may be that the research reviewed will have covered courses based on all the four models of 'context' and their different uses within the entire science curriculum. Their range in ontological and epistemological commitment will have obscured a detailed picture. As has been argued above, we certainly need to understand the precise notion of context underlying a given curriculum if we are to appreciate its educational value.

\title{
Curriculum development and implementation
}

\author{
Another explanation for the shortfall between aspiration and achievement is given by the \\ complex nature of curriculum development and the implementation of innovative ideas \\ into classroom-practice. Thus, the process of developing context-based approaches \\ deserves systematic attention. If the implementation of a context-based chemical \\ curriculum is to be more fully effective, its design must be based on a comprehensive \\ model of the processes involved. A suitable model, applicable to any change in any \\ curriculum, is one first suggested by Goodlad and then developed further by Van den \\ Akker (Goodlad, 1979; Van den Akker, 1998). It consists of six elements:
}


- The ideal curriculum: the original vision, basic philosophy, rationale and mission underlying it. Here, which model of context-in-curriculum is being adopted?

- The formal curriculum: the elaboration of the original version in the documentation about the course that will be made widely available. All design teams produce such paperwork.

- The perceived curriculum: how teachers, the main users of the formal curriculum, understand what it intends and implies.

- The operational curriculum: the nature and content of the interactions between teachers, students, and resource materials, which take place in the classroom.

- The experiential curriculum: the actual learning processes that the students undertake.

- The attained curriculum: the learning outcomes achieved by the students, as recorded in the results of their assessment.

In a perfect world, the ambitions of the ideal curriculum would be realised by all the students in the attained curriculum. Yet this is rarely so. Why? Any degradation is uneven between the steps of the implementation but cumulative in effect. The ideal curriculum may be too opaque to be capable of realisation given the prior knowledge of the students, the educational background of the teachers, and/or the resources of time and materials available. The formal curriculum may contain key words e.g. 'learning environment', 'collaborative working' that are defined in such a way as too leave too great a flexibility of interpretation open to teachers. The perceived curriculum may be influenced by teachers' and students' beliefs and attitudes that are inimical to what is intended. The 
operational curriculum may require knowledge, skills, and resources, that that the teachers and students do not generally possess. The experienced curriculum may involve students in the adoption of ways of learning that turn out to be unproductive in general practice. The methods used to assess the attained curriculum may not clearly reflect the successful of the implementation process.

So what can be done to bring about a fully successful context-based chemistry curriculum? I suggest that:

- The ideal curriculum be explicitly based on one, preferably the last, model of context-based curriculum, with the agreement of all the stakeholders on why this model represents a suitable address to the problems identified. This matter should be fully debated and recorded by a group that is representative of all the stakeholders in the new curriculum i.e. practicing chemists, national educational administrators, officials of assessment agencies, chemistry teacher educators, chemistry teachers from the full range of types of school likely to be involved, maybe parents and students. The debate should also address how a parsimonious selection of contexts could be related to those concepts which are most widely used throughout chemistry and on which learning should concentrate.

- The formal curriculum should address all the elements of the chosen model of context-based curriculum in detail, spelling out what they are and what they intend, this address being undertaken by all the stakeholders. This process would 
involve the construction of a context-based framework that meets all the four criteria for the 'use of contexts' in chemical education.

- The perceived curriculum should be preceded, associated with, and followed up by, an extensive programme of reformed pre- and in-service teacher education. It should take into account the existing beliefs of teachers and educators.

- The operational curriculum should be closely monitored by a well-founded team of evaluators whose task was to provide rapid feedback to the agency with oversight of the curriculum. Its evaluation should be based on the expectations that follow from the construction of the formal curriculum.

- The experiential curriculum should have a programme of classroom-based research associated with it;

- The attained curriculum should be assessed by methods that are fully compatible with the ideal curriculum.

The evaluation and research that takes place concerning the operational, experiential and attained curriculum can be used to provide timely feedback on the viability of the ideal curriculum and its (realistic) transformation into the formal curriculum.

\section{The analysis of the five cases of context-based chemistry education in this Special}

\section{Issue}


The papers that follow all focus on examples of development of context-based curricula for chemical education. By adopting this content focus, similarities and differences of ambition, organisation, and achievement, can be identified. The curricula reported on were developed in five countries: USA, England, Israel, Germany, and The Netherlands. They were initiated over a wide time span, so that some are now fully operational in many schools whilst others are at an early stage of development in just a few schools. The Van den Akker model given above has been used to provide a common framework for representation: only in the later-dated projects has the model being explicitly used in the conduct of the development.

Whilst the reader may wish to apply the ideas given earlier in this paper to each of the reported projects, there are some questions that transcend them all. For example, the question about the implication that the status of the project funding agency has for what was done and how it was done. Also the question of the relevance of modules developed in one country for the curriculum in another country with a different educational culture. Finally, the relevance of experience with context-based courses in chemical education to similar courses in other sciences.

\footnotetext{
Context-based chemical curricula are gaining popularity throughout the world. There is much to be done before we can be sure of the scope and limitations of the educational value of the genre. We can then determine the extent to which it successfully addresses the current problems of chemistry education.
} 


\section{Acknowledgements}

I am very grateful to Astrid Bulte and Albert Pilot for their thoughtful, detailed, sustained, and constructive critiques of the several earlier versions of this paper.

\section{References}

A.S.E. (1986). Science and Technology in Society. Hatfield: Association for Science Education.

Becker, J., \& Varelas, M. (1995). Assisting construction: the role of the teacher in assisting the learner's construction of pre-existing cultural knowledge. In L. P. Steffe \& J. Gale (Eds.), Constructivism in education (pp. 433-446). Hillsdale, New Jersey: Lawrence Erlbaum.

Bennett, J. (2003). Context-based approaches to the teaching of science. In Teaching and learning science (pp. 99-122). London: Continuum.

Braund, M., \& Reiss, M. (in press). Towards a more authentic science curriculum: The contribution of out-of-school learning. International Journal of Science Education. Bulte, A.M.W., Westbroek, H. B., Jong, O. de, \& Pilot, A. (this issue) A research approach to designing chemistry education using authentic practices as contexts. International Journal of Science Education. Campbell, B., Lazonby, J., Millar,R., Nicolson,P., Ramsden, J., \& Waddington, D. (1994). Science: The Salters' approach: a case study of the processes of large scale curriculum development. Science Education, 78(5), 415-448. 
Cobb, P., Stephan, M., McClain, K., \& Gravemeijer, K. (2001). Participating in classroom mathematical practices. The Journal of the Learning Sciences, 10(1\&2), 113163.

Confrey, J. (1995). How compatible are radical constructivism, sociocultural approaches and social constructivism? In L. P. Steffe \& J. Gale (Eds.), Constructivism in education (pp. 185-226). Hillsdale, New Jersey: Lawrence Erlbaum.

De Vos, W., Bulte, A. M. W., \& Pilot, A. (2002). Chemistry Curricula for General Education: Analysis and Elements of a Design. In J. K. Gilbert, O. De Jong, R. Justi, D. F. Treagust \& J. H. Van Driel (Eds.), Chemical Education: Towards Research-Based Practice (pp. 101-124). Dordrecht: Kluwer.

Duranti, A., \& Goodwin, C. (Eds.). (1992). Rethinking context: Language as an interactive phenomenon. Cambridge: Cambridge University Press.

Finkelstein, N. (2005). Learning physics in context: a study of student learning about electricity and magnetism. International Journal of Science Education, 27(10,1187-1209) George, J. M., \& Lubben, F. (2002). Facilitating teachers' professional growth through their involvement in creating context-based materials in science. International Journal of Educational Development, 22, 659-672.

Glaserfeld, E. V. (1989). Constructivism in education. Oxford: Pergamon Press. Goodlad, J. (1979). Curriculum enquiry: The study of curriculum practice. New York: McGraw-Hill. Greeno, J. (1998). The situativity of knowing, learning and research. American Psychologist, 53(1), 5-26. 
Kasanda, C., Lubben, F., Gaoseb, N., Kandjeo-Marenga, Kapenda, H., \& Campbell, B. (in press). The role of everyday contexts in learner-centred teaching: The practice in Namibian secondary schools. International Journal of Science Education.

Kelly, G. A. (1955). The psychology of personal constructs. New York: W.W. Norton. Laugksch, R. C. (2000). Scientific literacy: a conceptual overview. Science Education, 84(1), 71-94.

Layton, D. (1993). Technology's challenge to science education. Buckingham: Open University Press.

Lederman, N. G. (1992). Students' and teachers' conceptions of the nature of science: a review of the research. Journal of Research in Science Teaching, 29(4), 331-359.

Matthews, M. R. (1995). Constructivism and New Zealand science education. Auckland: Dunmore Press.

Mayoh, K., \& Knutton,S. (1997). Using out-of-school experiences in science lessons: reality or rhetoric? International Journal of Science Education, 19(7), 849-867.

Millar, R., \& Osborne, J. (2000). Beyond 2000: science education for the future. London: School of Education, King's College London.

Ogborn, J. (1997). Constructivist metaphors in science learning. Science and Education, $6(1-2), 121-133$.

Osborne, J. (1996). Beyond Constructivism. Science Education, 80(1), 53-82.

Osborne, J., \& Collins, S. (2000). Pupils' and parents views of the school science curriculum. London: King's College.

Pearsall, J. (Ed.). (1999). The Concise Oxford Dictionary. Oxford: Oxford University Press. 
Pope, M., \& Keen, T. (1981). Personal Construct Psychology in Education. London:

Academic Press.

Roberts, D. A. (1988). What Counts as Science Education? In P. J. Fensham (Ed.), Development and Dilemma's in Science Education (pp. 27-54). London: Palmer Press.

Roberts, D. A., \& Ostman, L. (1998). Problems of meaning in science curriculum. New York: Teachers College Press.

Rutherford, F., \& Ahlgren, A. (1990). Science for All Americans. New York: Oxford University Press.

Shulman, L. (1987). Knowledge and teaching: foundations of the new reforms. Harvard Educational Review, 57(1), 1-22.

Solomon, J. (1994). The rise and fall of constructivism. Studies in Science Education, 23, $1-19$.

Solomon, J., \& Aikenhead, G. (Ed.). (1994). STS education: International perspectives on reform. New York: Teachers College Press.

Stanitski, C. L., Eubanks, L. P., Middlecamp, C. H., \& Pienta, N. J. (2003). Chemistry in context: Applying chemistry to society. Boston: McGraw Hill.

Stocklmayer, S. M., \& Gilbert, J. K. (2002). Informal chemical education. In J. K.

Gilbert, De Jong, O., Justi, R.,Treagust, D.F., \& Van Driel, J.H. (Ed.), Chemical education: towards research-based practice (pp. 143-164). Dordrecht: Kluwer.

Strathern, P. (2000). Mendeleyev's dream. London: Hamish Hamilton.

Van Aalsvoort, J. (2004). Activity theory as a tool to address the problem of chemistry's lack of relevance in secondary school chemical education. International Journal of Science Education, 26(13), 1635-1651. 
Van den Akker, J. (1998). The science curriculum: Between ideals and outcomes. In B.

Frazer \& K. Tobin (Eds.), International Handbook of Science Education (Vol. 1, pp. 421447). Dordrecht, The Netherlands: Kluwer.

Van Oers, B. (1998). From context to decontextualizing. Learning and Instruction, 8(6), 473-488.

Vygotsky, L. S. (1978). Mind in society: the development of higher psychological processes. Cambridge, MA: Harvard University Press.

Wandersee, J. H., \& Roach,L.M. (1997). Interactive historical vignettes. In J. J. Mintzes, Wandersee, J.H., \& Novak, J.D. (Ed.), Teaching science for understanding (pp. 281-306). San Diego: Academic Press. 